\section{THE SHOOT'NG STARS OF THE JULY METEORIC EPOCH}

2

UETELET pointed out, many years ago, the period July $26-30$ as a meteoric epoch of considerable intensity, and recent observations have fully confirmed his opinion. There are two special showers contributing to this result, namely, the Aquariads and Perseids. The latter merely represents the oncoming of the great August display which culminates on the Ioth and then rapidly dies out.

This year, on July 28 th, the sky was very clear from clouds (though a little haze prevailed), and a fairly good opportunity was offered for witnessing these July meteors. It was important that this should be done, because the previous observations were not in satisfactory accordance. Professor Herschel in 1865 , July 28 th, had observed the chief radiant near the bright star Fomalhaut, and in I88I, July 25-30, M. Cruls of the Imperial Observatory at Rio Janeiro, found that the radiant point of more than 90 per cent. of the meteors observed during that period was situated five degrees north of Fomalhaut. In 1880, July 28-30, Mr. E. F. Sawyer, of Cambridgeport, Mass., found the major radiant to lie at $a 330^{\circ}, \delta-6^{\circ}$, with minor showers at $328^{\circ}-15^{\circ}$, and $341^{\circ}-10^{\circ}$. Colonel Tupman, who watched these meteors with considerable success and accuracy during the last few nights of July, 1870, determined the focus of divergence as at $340^{\circ}-14^{\circ}$, and the writer from observations at Bristol in 1878 and 1879 , corroborated this position, and found that in addition to these Aquariads, there was a very rich contemporary shower, directed from a point near the star cluster $\chi$ Persei.

Comparing the various observations to which we have just briefly referred, it will be seen that considerable doubt exists as to the exact centre of radiation of these July meteors. Obviously the point is either in Aquarius or further south in Piscis Australis, and near the conspicuous star Fomalhaut of that constellation. The observations also suggest that there may be several streams in marked activity at this epoch, and it was with the object of obtaining further evidence towards the settlement of this question, that I reobserved these meteors on the night of July 28 last.

I began watching the eastern heavens at 10.30 , and at 10. 36 a very fine meteor, as brilliant as Jupiter, appeared near $\gamma$ Andromedæ. It had a short path of only four degrees, and left a vivid streak. The meteor was evidently much foreshortened and close to its radiant point slightly west of $\chi$ Persei, so that it was an early forerunner of the Perseids. At II.4 another fine meteor, of exactly similar type, was seen falling between $a$ and $\beta$ Andromedæ, and at II.IO a third, considerably brighter and quite equal to Venus, traversed a path of nearly thirty degrees between Pegasus and Aquila, where it left a bright streak of some twenty degrees for a few seconds. Several other Perseids were observed later on, and the radiant point was found to lie at $27^{\circ}+55^{\circ}$, which conforms fairly well with the position I found for the same display in 1878 at $32^{\circ}+53^{\circ}$ (63 meteors). As to the expected shower of Aquariads I was not disappointed, though during the earlier part of the night only small ones were seen, and I could not get the position of the radiant with the necessary exactness. Between $13 \mathrm{~h}$. and $14 \mathrm{~h}$. however, I saw eight Aquariads, and three of these were brilliant. At I 3 h. I $3 \mathrm{~m}$. one appeared just below $\beta$ Andromedæ. It was brighter than a first magnitude star. At $13 \mathrm{~h} .37 \mathrm{~m}$. a fine Aquariad, rivalling Jupiter, was seen in the west region of Pisces, and at $13 \mathrm{~h}$. $54 \mathrm{~m}$. another of the first magnitude appeared in nearly the same place. They moved slowly and left trains of sparks.

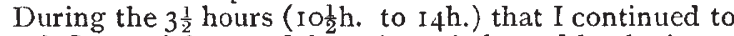
watch I saw eighteen of these Aquariads, and by the intersection of the paths, found the radiant very sharply defined at $337^{\circ}-\mathrm{II}^{\circ}$, and close to the point I had determined in I 878 and 1879. This shower was far superior to the Perseids in the morning hours, and fully asserted its claim to be considered as the special display of the epoch. The meteors generally have long paths, as the radiant point is not far above the horizon. In all I saw 48 meteors during the night, and of these no less than 28 belonged either to the Perseids or Aquariads.

There can be no doubt that these July Perseids are identical with the celebrated shower of August 10, though the radiant point is some $8^{\circ}$ west in July. I have watched these Perseids very carefully from July 25 up to August 16 in several years, and traced the gradual shifting of the radiant point. From my observations during the last week of July, I878, I had supposed these July Perseids to form a distinct shower to the Perseids of August Io, but from observations obtained on intermediate dates, i.e. on August 3, 4, and 5, the connection of the two showers is most certainly established, and the displacement of the radiant point on each successive night can be clearly distinguished by those who will mark the tracks of such meteors as appear near this radiant from say July 25 to August 15 .

As to the Aquariads, I believe the maximum takes place on July $27-28$, when they are undoubtedly more numerous than the early Perseids. I feel certain that the radiant point is near $\delta$ Aquarii or at $339^{\circ}-13^{\circ}$. There is another shower near Fomalhaut, which appears to have developed remarkable energy in I88I from M. Cruls' observations, and there are also other showers in Aquarius at this special period, which have led to the difficulty in determining the position of the major radiant. There is certainly a very fine shower of meteors at the end of July from a point a few degrees S.E. of $\beta$ Aquarii, which has been observed as follows :-

$$
\begin{array}{rllllll} 
& \text { July } 25-31 & \ldots & \ldots & \ldots & 324-6 & \text { Schmidt. } \\
\text { 1870 } & \text { July } 28 & \ldots & \ldots & \ldots & 326-13 & \text { Tupman. } \\
\text { 1880 } & \text { July } 28-30 & \ldots & \ldots & \ldots & 328-15 & \text { Sawyer. } \\
& \text { July } 25-31 & \ldots & \ldots & \ldots & 324-9 & \text { Denning. }
\end{array}
$$

I gave some details of this particular stream, which, it may be added, is one remarkable for its large meteors, in the Monthly Notices of the Royal Astronomical Society for November, I88I, p. 38.

It now becomes important to watch for the annual returns of these meteors of the July epoch at observatories in the southern hemisphere, where they may be more favourably observed than in high northern latitudes. Obviously, a shower near Fomalhaut will be in a great measure marred by the extremely low altitude of the radiant, as that star never attains an altitude even of $10^{\circ}$ in this country. At stations further south, the shower of Aquariads appears to be one of great strength and to form a display of first-class importance. Observations made in 1879 show a wide disparity in the number of these meteors visible in different latitudes. Mr. D. W. Barker, during a voyage from London to Melbourne (Monthly Notices, Vol. XL., p. 364), in that year observed meteors falling at the rate of 180 per hour on July 28 and 120 per hour on July 29 , between oh. and $4 \mathrm{~h}$. a.m. on the dates referred to. Yet, at Bristol on July 28 of the same year, the hourly number was only 23 , and on July $29, \mathrm{I}$.

The further investigation of the July meteoric epoch offers an attractive field to observers. Apart from the rich shower of Aquariads there are the Perseids, equally interesting from the fact that these early members of the great shower prove it to be one of long duration, and to have a radiant point which shifts its position amongst the stars from night to night. These interesting details will no doubt come under frequent observation in future years.

\section{W. F. DENNING}

